\title{
IN VITRO AND IN VIVO EVALUATION OF A SUSTAINED RELEASE PREPARATION CONTAINING PHENYLPROPANOLAMINE HYDRO- CHLORIDE
}

\author{
ICHIRo Yamakawa, * Masao Shimomura, Telichi Hattori, Sumio Watanabe, Junzou \\ TSUTSUMI, AISHIN SHINODA AND YASUO MIYAKE
}

Research Laboratories of Pharmaceutical Development, Eisai Co., Ltd., Kawashima-cho, Hashima-gun, Gifu, 483, Japan

(Received April 25, 1986)

The relationship between dissolution behaviour and plasma concentration after administration of a sustained-release preparation containing phenylpropanolamine hydrochloride was studied in 11 male volunteers. The testing for dissolution was carried out using the JP X rotating basket procedure, and human plasma samples were assayed for phenylpropanolamine hydrochloride by a specific high-performance liquid chromatography. Three hours after dosing, the mean peak plasma concentration was $104.1 \mathrm{ng} / \mathrm{ml}$ and the plasma concentration declined with a half-life of $4.85 \mathrm{~h}$. The time course of plasma and dissolution data were analyzed by a non-linear least squares curve fitting method to compare in vivo and in vitro release behaviour. Plasma concentration changes of phenylpropanolamine hydrochloride were correlated with in vitro release behaviour of the sustained-release preparation.

Keywords — phenylpropanolamine hydrochloride; sustained-release; dissolution test; human plasma; pharmacokinetics

\section{INTRODUCTION}

Phenylpropanolamine hydrochloride (PPA$\mathrm{HCl}$ ), used as a nasal decongestant, is rapidly and completely absorbed in the intestine, and has been widely used as a long-acting dosage form owing to its biological half-life of $2-3$ h. $^{11}$ Many studies on the absorption kinetics of several prolonged-release products containing PPA$\mathrm{HCl}$ have been reported. ${ }^{2-5)}$

Lindberg et al., ${ }^{2)}$ for example, showed that the in vitro release rate from a prolonged acting tablet reflected the actual net rate excretionversus-time profile using Wiegand and Taylor's equation. ${ }^{6)}$ Tomida et al. ${ }^{3)}$ studied in vitro dissolution test method for wax-coated beads and compared the results with an in vivo data. These previous reports on the comparison of in vitro and in vivo data were restricted to the urinary excretion profiles of slow-release PPA-HCl.

Barrett et al. ${ }^{4)}$ and Lönnerholm et al. ${ }^{5)}$ studied bioavailability of PPA- $\mathrm{HCl}$ during a dose interval in steady-state after the administration of a sustained-release preparation. However, no comparison of in vitro and in vivo data was made. Little work, therefore, has been done on the quantitative relationship between in vitro release and plasma concentration changes after the administration of a sustained-release preparation showing a rapid-release phase followed by a slow-release phase.

In this study, the in vitro and in vivo release rates of a sustained-release preparation in healthy male volunteers were investigated on the basis of a pharmacokinetic model using a non-linear least squares curve fitting method.

\section{EXPERIMENTAL}

Dosage Form — The sustained-release preparation was in the form of uncoated and ethylcellulose-coated beads (590-840 $\mu$ m diameter) filled in hard gelatin capsules containing $40 \mathrm{mg}$ of PPA-HCl. This product was prepared in the laboratory.

Twenty five mg of PPA- $\mathrm{HCl}$ was usually applied 3 or 4 times daily as the rapid-release dosage form. ${ }^{7)}$ Taking this conventional usage into consideration, the authors decided the rapid-release dose and the slow-release rate constant arbitrarily to dissolve $25 \mathrm{mg}$ of PPA-HCl in $1-2 \mathrm{~h}$.

PPA- $\mathrm{HCl}$ is often used by allergic rhinit is patients with an anti-histaminic drug and an anti-

\footnotetext{
* Present address: Tsukuba Research Laboratories, Eisai Co., Ltd., Tokodai, Toyosato-cho, Tsukuba-gun, Ibaraki, 300-26,
} Japan. 
cholinergic drug, as a combination product. The sustained-release preparation used in this study also contained $4 \mathrm{mg}$ of chlorpheniramine maleate and $0.2 \mathrm{mg}$ of belladonna alkaloids.

In Vitro Evaluation —Dissolution testing was carried out according to the JP X rotating basket method. A covered $1000 \mathrm{ml}$ beaker containing with $900 \mathrm{ml}$ of dissolution medium was immersed in a $37^{\circ} \mathrm{C}$ constant temperature bath and the solution was stirred at $100 \mathrm{rpm}$. Speeds of 50 and $150 \mathrm{rpm}$ were also used to examine the effect of rotating speed on the dissolution behaviour.

Since sustained-release preparations pass through the upper gastrointestinal tract, the in vitro dissolution test was performed at its $\mathrm{pH}$ range. Davis et al. ${ }^{8)}$ showed the gastric emptying profile of pellets for fasting or light mealconsuming volunteers using a scintigraphic method. Although there was intersubject variation, more than $80 \%$ of the pellets emptied from the stomach in $2 \mathrm{~h}$. Therefore, the exposure to the acid medium was limited to $2 \mathrm{~h}$ in this study.

The dissolution medium for the JP $\mathrm{X}$ first solution was at $\mathrm{pH} 1.2$ and the acetate buffer solutions were $\mathrm{pH} 4.0$ and then $\mathrm{pH} 5.0$ during the initial $2 \mathrm{~h}$. Subsequently, the beaker was removed and replaced with the JP X second solution $\mathrm{pH} 6.8$.

In Vivo Evaluation - Eleven healthy male subjects, 22-41 years old and 57-77 kg (mean $68.0 \mathrm{~kg}$ ) were studied. They did not receive any drugs, nor any alcoholic or caffeine-containing beverages. The subjects were not allowed food overnight, from $12 \mathrm{~h}$ before to $3 \mathrm{~h}$ after administration. Each subject received one sustainedrelease capsule containing $40 \mathrm{mg}$ of $\mathrm{PPA}-\mathrm{HCl}$ with $150 \mathrm{ml}$ of water. Serial blood samples were collected over a $24 \mathrm{~h}$ period and the plasma from the blood frozen immediately and kept frozen until assayed.

Determination of Phenylpropanolamine in Human Plasma — The paired ion chromatographic method described by Misaki was modified. ${ }^{9)}$ Chlorprenaline hydrochloride was used as the internal standard. Two $\mathrm{ml}$ of plasma samples were mixed with $2 \mu \mathrm{g}$ of the internal standard, $0.5 \mathrm{ml}$ of $1 \mathrm{~N} \mathrm{NaOH}$ and $0.35 \mathrm{~g}$ of $\mathrm{NaCl}$. The mixture was extracted twice by shak- ing for $10 \mathrm{~min}$ with $4 \mathrm{ml}$ of dichlormethane and ethylether $(30: 70)$. The two organic extracts were combined and extracted with $0.5 \mathrm{ml}$ of $0.5 \%$ phosphoric acid by shaking for $30 \mathrm{~min}$. Following centrifugation for $10 \mathrm{~min}$ at $3000 \mathrm{rpm}$, $100 \mu \mathrm{l}$ of the aqueous layer was injected into an high-performance liquid chromatography (HPLC).

Chromatography was performed with a $\mathrm{Nu}$ cleosil $\mathrm{C}_{18}(10 \mu)$ column $(25-\mathrm{cm} \times 4.6-\mathrm{mm}$ i.d. $)$ with a mobile phase of acetonitrile and $0.2 \%$ phosphoric acid aqueous solution containing $0.01 \mathrm{M}$ sodium lauryl sulphate $(40: 60)$. This mobile phase was used at a flow rate of $2 \mathrm{ml} / \mathrm{min}$ and the temperature of the column was maintained at $35^{\circ} \mathrm{C}$. The wavelength of detection was $210 \mathrm{~nm}$. Peak height ratios were converted to concentrations using a calibration curve for a PPA-HCl concentration range of $0.02-5 \mu \mathrm{g} / \mathrm{ml}$.

Kinetic Analysis — In Vitro: The time course data of percentages dissolved were fitted to Eqs. 1 and 2.

$$
\begin{gathered}
y(\%)=0 \quad \text { for } t \leqq \Delta t \\
\begin{array}{c}
y(\%)=k_{\mathrm{r}} \cdot(t-\Delta t)+b \cdot\left(1-e^{-k_{i} \cdot(t-\Delta t)}\right) \\
\text { for } \Delta t<t \leqq \tau
\end{array}
\end{gathered}
$$

$y$, percentages dissolved (\%);

$k_{\mathrm{i}}$, first-order release rate constant from a rapidrelease dose $\left(\mathrm{h}^{-1}\right)$;

$k_{\mathrm{r}}$, zero-order release rate constant from a slowrelease dose $(\% / \mathrm{h})$;

$b$, total percent dissolved from a rapid-release dose $(\%)$;

$\tau$, time taken for a slow-release dose to dissolve completely (h);

$\Delta t$, lag time (h).

The value of $b$ was limited to $\leqq 50$ in this calculation.

In Vivo: The time course data of the plasma levels were fitted to Eqs. 3,4 and 5 represented by Chart $1,{ }^{10)}$ where $k_{\mathrm{i}}$ and $k_{\mathrm{r}}$ were first-order and zero-order release rate constants, respectively. These pharmacokinetic parameters were obtained by a non-linear least squares method.*

$C_{\mathrm{p}}(\mathrm{ng} / \mathrm{ml})=0 \quad$ for $t \leqq \Delta t$

* "NONLIN '74"; Metzler C.M.; The Upjohn Co. 


$$
\begin{aligned}
C_{\mathrm{p}}(\mathrm{ng} / \mathrm{ml})= & \frac{10^{3} \cdot f \cdot D_{\mathrm{fi}}}{V_{\mathrm{d}}} \cdot k_{\mathrm{i}} \cdot k_{\mathrm{a}}\left[\frac{e^{-k_{\mathrm{a}}(t-\Delta t)}}{\left(k_{\mathrm{e}}-k_{\mathrm{a}}\right)\left(k_{\mathrm{i}}-k_{\mathrm{a}}\right)}+\frac{e^{-k_{\mathrm{i}}(t-\Delta t)}}{\left(k_{\mathrm{a}}-k_{\mathrm{i}}\right)\left(k_{\mathrm{e}}-k_{\mathrm{i}}\right)}\right. \\
& \left.+\frac{e^{-k_{\mathrm{e}}(t-\Delta t)}}{\left(k_{\mathrm{i}}-k_{\mathrm{e}}\right)\left(k_{\mathrm{a}}-k_{\mathrm{e}}\right)}\right]+\frac{10 \cdot k_{\mathrm{r}} \cdot D_{\mathrm{T}}}{V_{\mathrm{d}}}\left\{\frac{1}{k_{\mathrm{e}}}\left[1-e^{-k_{\mathrm{e}}(t-\Delta t)}\right]\right. \\
& \left.+\frac{1}{k_{\mathrm{a}}-k_{\mathrm{e}}}\left[e^{-k_{\mathrm{a}}(t-\Delta t)}-e^{-k_{\mathrm{e}}(t-\Delta t)}\right]\right\} \\
& \text { for } \Delta t<t \leqq \tau
\end{aligned}
$$

$$
\begin{aligned}
C_{\mathrm{p}}(\mathrm{ng} / \mathrm{ml})= & \frac{10^{3} \cdot f \cdot D_{\mathrm{fi}}}{V_{\mathrm{d}}} \cdot k_{\mathrm{i}} \cdot k_{\mathrm{a}}\left[\frac{e^{-k_{\mathrm{a}}(t-\Delta t)}}{\left(k_{\mathrm{e}}-k_{\mathrm{a}}\right)\left(k_{\mathrm{i}}-k_{\mathrm{a}}\right)}+\frac{e^{-k_{\mathrm{i}}(t-\Delta t)}}{\left(k_{\mathrm{a}}-k_{\mathrm{i}}\right)\left(k_{\mathrm{e}}-k_{\mathrm{i}}\right)}\right. \\
& \left.+\frac{e^{-k_{\mathrm{e}}(t-\Delta t)}}{\left(k_{\mathrm{i}}-k_{\mathrm{e}}\right)\left(k_{\mathrm{a}}-k_{\mathrm{e}}\right)}\right]+\frac{10 \cdot k_{\mathrm{r}} \cdot D_{\mathrm{T}}}{V_{\mathrm{d}}}\left\{\frac{1}{k_{\mathrm{e}}}\left[1-e^{-k_{\mathrm{e}}(\tau-\Delta t)}\right]\right. \\
& \left.+\frac{1}{k_{\mathrm{a}}-k_{\mathrm{e}}} \cdot\left[e^{-k_{\mathrm{a}}(\tau-\Delta t)}-e^{-k_{\mathrm{e}}(\tau-\Delta t)}\right]\right\} \cdot e^{-k_{e}(t-\tau)} \\
& +\frac{10 \cdot k_{\mathrm{r}} \cdot D_{\mathrm{T}}}{V_{\mathrm{d}} \cdot\left(k_{\mathrm{a}}-k_{\mathrm{e}}\right)} \cdot\left[1-e^{-k_{\mathrm{a}}(\tau-\Delta t)}\right]\left[e^{-k_{\mathrm{e}}(t-\tau)}-e^{-k_{\mathrm{a}}(t-\tau)}\right] \\
& \text { for } \tau<t
\end{aligned}
$$

$C_{\mathrm{p}}$, plasma concentration $(\mathrm{ng} / \mathrm{ml})$

$V_{\mathrm{d}}$, distribution volume (1);

$k_{\mathrm{a}}, \quad$ absorption rate constant $\left(\mathrm{h}^{-1}\right)$;

$k_{\mathrm{e}}$, elimination rate constant $\left(\mathrm{h}^{-1}\right)$;

$D_{\mathrm{T}}$, a total dose $(\mathrm{mg})=40 \mathrm{mg}$ in this preparation;

\section{RESULTS AND DISCUSSION}

\section{In Vitro Evaluation}

The dissolution profiles of PPA- $\mathrm{HCl}$ are shown in Figs 1 and 2 . The difference in percentages of the dissolved-time data was not significant at $\mathrm{pH} \mathrm{1.2,4.0,} \mathrm{and} 5.0$ for the initial $2 \mathrm{~h}$, and at subsequent $\mathrm{pH} 6.8$ for $6 \mathrm{~h}$. The effect of the rotating speeds was not observed in the range of $50-150 \mathrm{rpm}$. These test conditions did not affect the drug release from the sustained-release preparation.

In the following discussion, the condition of the dissolution test at a rotating speed of 100 $\mathrm{rpm}$ with a medium of $\mathrm{pH} 1.2$ for the initial $2 \mathrm{~h}$, and subsequent $\mathrm{pH}$ 6.8, was used as a typical in vitro evaluation.

The simulated curve of percentages of the dissolved-time data using Eqs. 1 and 2 for the typical dissolution test condition is shown as a
$D_{\text {fi }}, \quad$ a rapid-release dose $(\mathrm{mg})=20 \mathrm{mg}$ in this preparation;

$f$, a fraction of drug absorbed from a rapidrelease dose.

Other abbreviations were used as well as in vitro kinetic analysis.

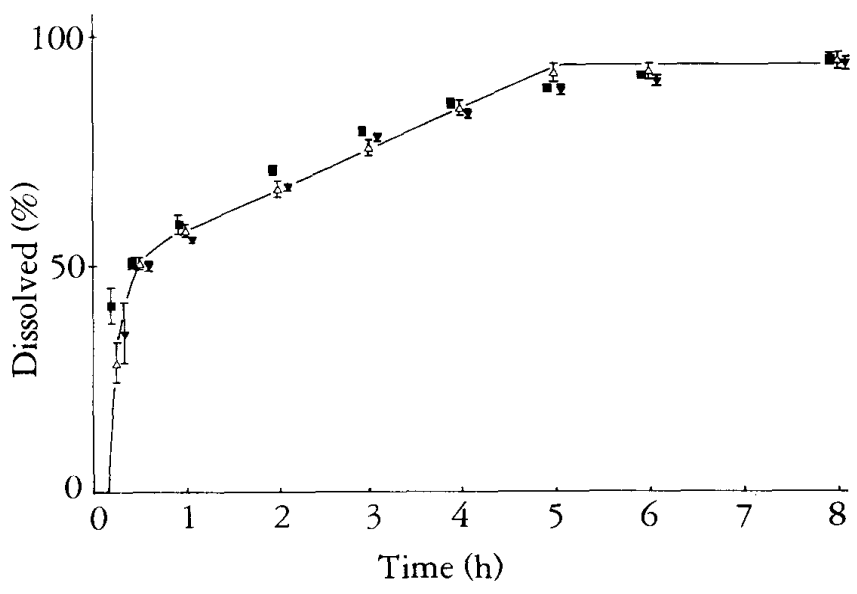

FIG. 1. Effect of $p H$ for the Initial $2 h$ on the Dissolution Profiles at a Rotating Speed of $100 \mathrm{rpm}$ Each points represent the mean $\pm S E M(n=$ 3). $\triangle, p H ~ 1.2 ; \mathbf{\square}, p H 4.0 ; \nabla, p H 5.0 ;-$ simulated curve for $\mathrm{pH} 1.2$. 


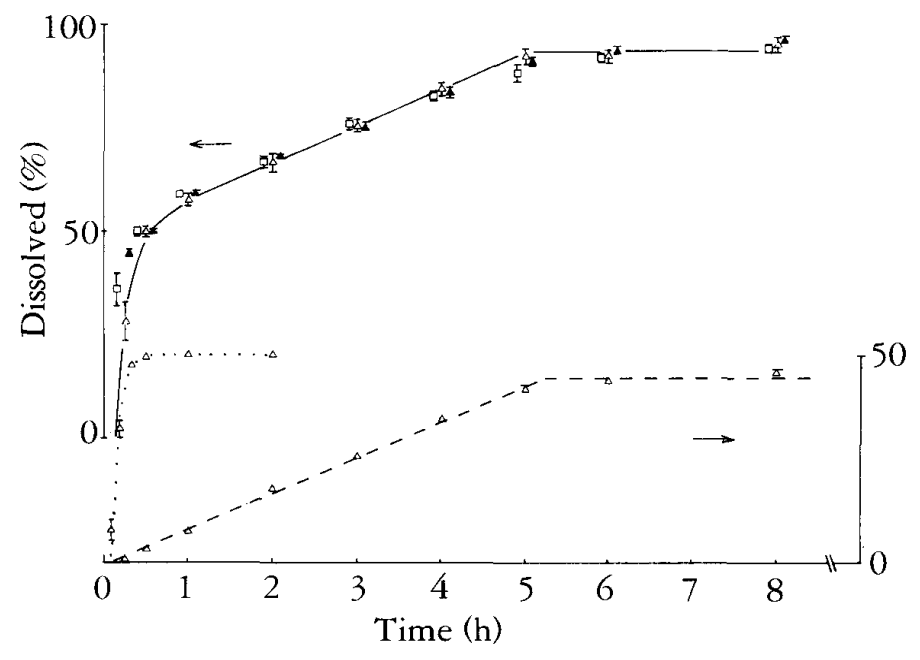

FIG. 2

Upper: Effect of the rotating speed on the dissolution profiles at $\mathrm{pH} 1.2$ for the initial $2 \mathrm{~h}$, and at subsequent $\mathrm{pH} 6.8$ for the remaining time.

Each points represent the mean $\pm S E M(n=$ 3). $\square, 50 \mathrm{rpm} ; \triangle, 100 \mathrm{rpm} ; \boldsymbol{\Delta}, 150 \mathrm{rpm} ;-$ simulated curve.

Lower: Dissolution profiles for the rapid-release beads alone and for the slow-release beads alone are shown as a dotted line (...) and a broken line (---), respectively.

solid line. The rapid-release curve, fitted to a first-order term in Eq. 2, is shown as a dotted line, and the slow-release curve, fitted to a zeroorder term in Eq. 2, is shown as a broken line.

A lag time of $4-8$ min was observed for these curves, corresponding to the time required for the gelatin shell to dissolve. The lag time of the rapid-release curve was nearly equal to that of the slow-release curve in Fig. 2. Based on the in vitro release behaviour, equality of lag time between a rapid-release phase and a slow-release phase was assumed in this study.

In vitro release parameters obtained for the dissolution curves in Fig. 2 are listed in Table I.

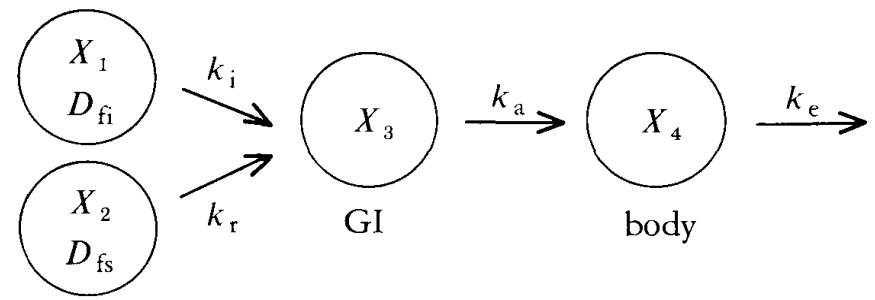

CHART 1. Kinetic Model for Sustained-Release

The difference in the release rate constants was not significant, but the first-order release rate for the rapid-release phase in the sustainedrelease preparation was slightly slower than the first-order release rate for the rapid-release beads alone. This may be caused by the slightly slow disassociation of the capsule. The zeroorder release rate constant for the slow-release phase in the sustained-release preparation agreed well with the zero-order release rate constant in the slow-release beads alone.

\section{In Vivo Evaluation}

Figure 3 shows the plasma concentration versus time data of PPA-HCl. The mean peak plasma concentration of PPA- $\mathrm{HCl}$ was $104.1 \pm$ $8.0 \mathrm{ng} / \mathrm{ml}$ (mean $\pm \mathrm{SEM}$ ) at $3 \mathrm{~h}$ and the plasma concentration declined at a half-life of $4.85 \pm$ $0.17 \mathrm{~h}$.

The changes in plasma levels with time were described by an open one compartment model (Chart 1), ${ }^{2)}$ and the pharmacokinetic parameters for each individual are listed in Table II.

The simulated curve of plasma concentrationtime data with Eqs. 3, 4 and 5 is shown as a solid line in Fig. 3. The relatively good agreement between the observed and the calculated values for plasma levels validates the pharmacokinetic model.

An in vivo zero-order release rate constant,

TABLE I. In Vitro Release Parameters for Sustained-Release Beads in a Typical Dissolution Test Condition $^{a)}$

\begin{tabular}{lcccc}
\hline \hline Sample beads & $k_{\mathrm{r}}(\mathrm{mg} / \mathrm{h})$ & $k_{\mathrm{i}}\left(\mathrm{h}^{-1}\right)$ & $\tau(\mathrm{h})$ & $\Delta t(\mathrm{~h})$ \\
\hline Rapid + slow & $3.63 \pm 0.17^{b)}$ & $8.61 \pm 0.72$ & $5.04 \pm 0.12$ & $0.146 \pm 0.028$ \\
Rapid & - & $10.92 \pm 1.82$ & - & $0.064 \pm 0.007$ \\
Slow & $3.50 \pm 0.05$ & - & $5.26 \pm 0.07$ & $0.100 \pm 0.032$ \\
\hline
\end{tabular}

a) The dissolution test was carried out at a rotating speed of $100 \mathrm{rpm}$ with a medium at $\mathrm{pH} 1.2$ for the initial $2 h$, and then at $p H$ 6.8. b) Data are expressed as the mean $\pm \operatorname{SEM}(n=3)$. 
TABLE II. Pharmacokinetic Parameters for Phenylpropanolamine Obtained from Plasma Concentration-Time Data

\begin{tabular}{rccccccccccc}
\hline \hline $\begin{array}{c}\text { Sub } \\
\text { No. }\end{array}$ & Age & $\begin{array}{c}\text { Body } \\
\text { weight } \\
(\mathrm{kg})\end{array}$ & $\begin{array}{c}f \cdot D_{\mathrm{fi}} / V_{\mathrm{d}} \\
(\mathrm{ng} / \mathrm{ml})\end{array}$ & $\begin{array}{c}k_{\mathrm{r}} / V_{\mathrm{d}} \\
(\mathrm{ng} / \mathrm{ml} \cdot \mathrm{h})\end{array}$ & $\begin{array}{c}k_{\mathrm{e}} \\
\left(\mathrm{h}^{-1}\right)\end{array}$ & $\begin{array}{c}k_{\mathrm{i}} \\
\left(\mathrm{h}^{-1}\right)\end{array}$ & $\begin{array}{c}\tau \\
(\mathrm{h})\end{array}$ & $\begin{array}{c}\Delta t \\
(\mathrm{~h})\end{array}$ & $\begin{array}{c}k_{\mathrm{a}} \\
\left(\mathrm{h}^{-1}\right)\end{array}$ & $\begin{array}{c}k_{\mathrm{r}} \\
(\mathrm{mg} / \mathrm{h})\end{array}$ & $\left.\mathrm{SS}^{a}\right)$ \\
\hline 1 & 22 & 57 & 82.42 & 18.57 & 0.175 & 80.00 & 4.31 & 0.309 & 9.82 & 4.51 & 86.8 \\
2 & 24 & 68 & 66.22 & 13.84 & 0.143 & 5.19 & 4.07 & 0.213 & 4.99 & 4.18 & 189.7 \\
3 & 27 & 77 & 87.69 & 13.12 & 0.109 & 75.14 & 2.80 & 0.297 & 10.00 & 2.99 & 375.1 \\
4 & 25 & 67 & 103.52 & 29.06 & 0.148 & 31.44 & 3.30 & 0.179 & 0.969 & 5.61 & 131.9 \\
5 & 34 & 70 & 91.27 & 11.19 & 0.131 & 7.29 & 4.15 & 0.259 & 7.10 & 2.45 & 189.7 \\
6 & 34 & 69 & 90.95 & 20.76 & 0.143 & 4.43 & 2.98 & 0.163 & 2.81 & 4.57 & 272.9 \\
7 & 36 & 64 & 58.98 & 22.08 & 0.158 & 5.85 & 4.12 & 0.095 & 4.92 & 7.49 & 23.2 \\
8 & 41 & 68 & 76.89 & 12.99 & 0.134 & 4.72 & 4.48 & 0.293 & 4.99 & 3.38 & 55.1 \\
9 & 41 & 67 & 118.85 & 26.68 & 0.176 & 4.03 & 3.94 & 0.150 & 4.22 & 4.49 & 27.9 \\
10 & 23 & 65 & 132.24 & 35.52 & 0.166 & 34.93 & 2.96 & 0.463 & 10.00 & 5.37 & 414.6 \\
11 & 26 & 76 & 132.26 & 4.70 & 0.137 & 3.69 & 4.60 & 0.068 & 2.04 & 0.71 & 470.9 \\
& & & & & & & & & & & \\
$\bar{x}$ & 30.3 & 68.0 & 94.66 & 18.96 & 0.147 & 23.34 & 3.79 & 0.226 & 5.62 & 4.16 & - \\
SEM & 2.0 & 1.6 & 7.11 & 2.58 & 0.006 & 8.36 & 0.19 & 0.033 & 0.93 & 0.51 & - \\
\hline
\end{tabular}

a) Residual sum of squares (SS) was calculated by $S S=\Sigma W_{i} \cdot\left(C_{i}(\text { obs. })-C_{i}(\text { cal. })\right)^{2}$, where $W_{i}$ was weight of points. A weight of unity was employed.

$k_{\mathrm{r}}$, was calculated from parameters in Table II on the assumption that the fraction of the drug absorbed $(f)$ from the rapid-release dose $\left(D_{\mathrm{fi}}=\right.$ $20 \mathrm{mg}$ ) was 1.0. This assumption is supported by the result that urinary recoveries of PPA-HCl after oral administration in man were about $80-100 \%$ in 24 h. $^{2,3,5)}$

There was a considerable intersubject variation in first-order release rate constants $\left(k_{\mathrm{i}}\right)$ from a rapid-release dose as shown in Table II. This may be attributed to the intersubject variation in the drug release process in the stomach, such as the disassociation of the capsule contents from the gelatin shell.

The values of $k_{\mathrm{i}}$ were not smaller compared with the absorption rate constants $\left(k_{\mathrm{a}}\right)$ in almost all subjects, indicating that the rate-limiting step in the absorption of PPA- $\mathrm{HCl}$ as a rapid-release phase was not the drug release process.

Comparison of in vitro and in vivo parameters in Tables I and II gave a relatively small difference in zero-order release rate constants $\left(k_{\mathrm{r}}\right)$ from the slow-release dose $\left(D_{\mathrm{fs}}\right)$ (in vitro, 3.63 $\pm 0.17 \mathrm{mg} / \mathrm{h}$; in vivo, $4.16 \pm 0.51 \mathrm{mg} / \mathrm{h}$ ). Consequently, a zero-order release phase contributed to the duration of plasma levels.

In Fig. 3, the "dash-dot" line shows the curve calculated by subsituting in vitro release rate

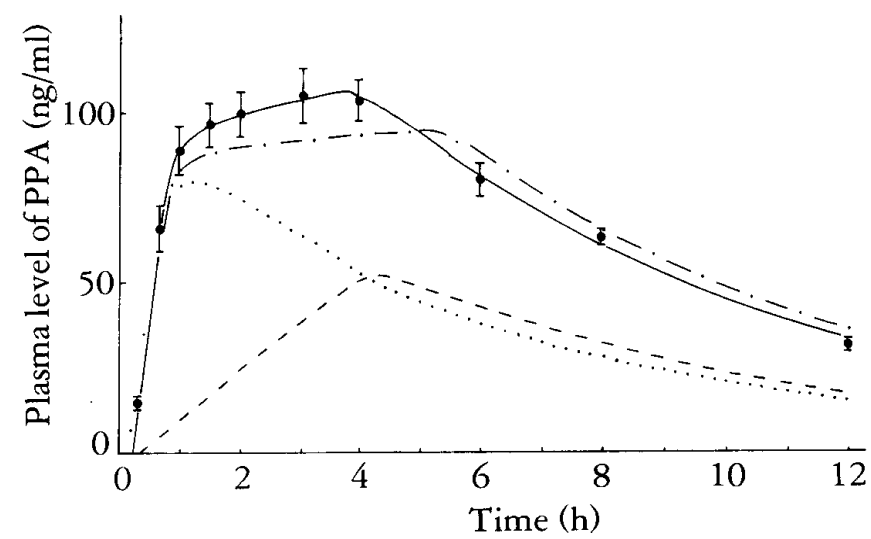

FIG. 3. Plasma Concentration-Time Data (○) of Phenylpropanolamine Hydrochloride after a Single Dose in 11 Male Volunteers (Mean \pm $S E M)$

The figure shows the simulated curve from the plasma concentration-time data (-), the calculated curve with Eqs. 3-5 by substituting in vitro release rate constants, $3.63 \mathrm{mg} / \mathrm{h}$ and 8.61 $h^{-1}$ for $k_{r}$ and $k_{i}$ in Chart $1(---)$ and the predicted individual contributions to the plasma concentration-time profile from $D_{f i}(\ldots)$ and $D_{f s}$ (---).

constants $\left(3.63 \mathrm{mg} / \mathrm{h}, 8.61 \mathrm{~h}^{-1}\right)$ for $k_{\mathrm{r}}$ and $k_{\mathrm{i}}$ in Chart 1 . Both the in vivo and in vitro curves have almost the same profiles throughout the period 
of measurement.

It was demonstrated, therefore, that the release behaviour of PPA-HCl in the gastrointestinal lumen was considerably reflected in the in vitro dissolution test according to the JP $\mathrm{X}$ rotating basket proocedure.

In addition, individual contributions from the rapid-release dose and the slow-release dose to the plasma concentration-time profile were separated on the basis of the pharmacokinetic parameters in Table II. Plasma levels can be maintained above the peak value of the dotted line for a relatively long period of time as seen in Fig. 3. This sustained-release action was almost in agreement with the objective for which it was designed.

These profiles (Fig. 3) based on the pharmacokinetic model were helpful in understanding sustained-release action.

In this study, it was demonstrated that the in vitro dissolution model of a sustained-release preparation with a rapid-release phase followed by a slow-release phase, can be introduced into in vivo pharmacokinetics. A reasonable good correlation was found between the in vitro dissolution behaviour and the in vivo performance of PPA-HCl. This may be mainly due to biological characteristics of PPA-HCl such as rapid and complete absorption by the oral route. However, the evaluating process in the present study appears to be useful for designing sustained-release formulation of drugs without poor absorption and/or first-pass characteristics.

\section{REFERENCES}

1) J. Kanfer, J. M. Haigh and R. Dowse: Phenylpropanolamine hydrochloride, Anal. Profiles Drug Subst., 12, 357-383 (1983).

2) N. O. Lindberg and C. G. A. Perrson: In vitro and in vivo evaluation of sustained release tablets containing norephedrine chloride, Acta Pharm. Suec., 9, $237-248$ (1972).

3) Y. Tomida, S. Yokohama, M. Maki, H. Toguchi and T. Shimamoto: In vitro dissolution test correlating quantitatively with sustained release phenylpropanolamine absorption in man, J. Takeda Res. Lab., 36 (1/2), 83-89 (1977).

4) W. E. Barrett, J. J. Banigan and D. L. Snyder: The bioavailability of sustained-release tablets which contain phenylpropanolamine and chlorpheniramine, Current Therapeutic Research, 30,640-654 (1981).

5) G. Lönnerholm, A. Grahnér and B. Lindström: Steadystate kinetics of sustained-release phenylpropanolamine, Int. J. Clin. Pharmacol., Ther. Toxicol., 22, 39-41 (1984).

6) R. G. W iegand and J. D. Taylor: Kinetics of plasma drug levels after sustained release dosage, Biochem. Pharmacol., 3, 256-263 (1960).

7) E. R. Barnhart: "Physician's Desk Reference," 39 ed., Medical Economics Co., Oradell, 1985.

8) S. S. Davis, J. G. Hardy, M. J. Taylor, D. R. Whalley and C. G. Wilson: A comparative study of the gastrointestinal transit of a pellet and tablet for mulation, Int. J. Pharm., 21, 167-177 (1984).

9) T. Misaki, T. Yoshida, Y. Nakazima, K. Hanada and H. Yoshizawa: Abstract of Papers, The 101 th Annual Meeting of the Pharmaceutical Society of Japan, Kumamoto, April 1981, p.136.

10) P. G. Welling and M. R. Dobrinska: "Sustained and Controlled Release Drug Delivery Systems," ed. by J. R. Robinson, Marcel Dekker, New York, 1978, pp. $631-716$. 